\title{
How much variance in insulin resistance is explained by obesity?
}

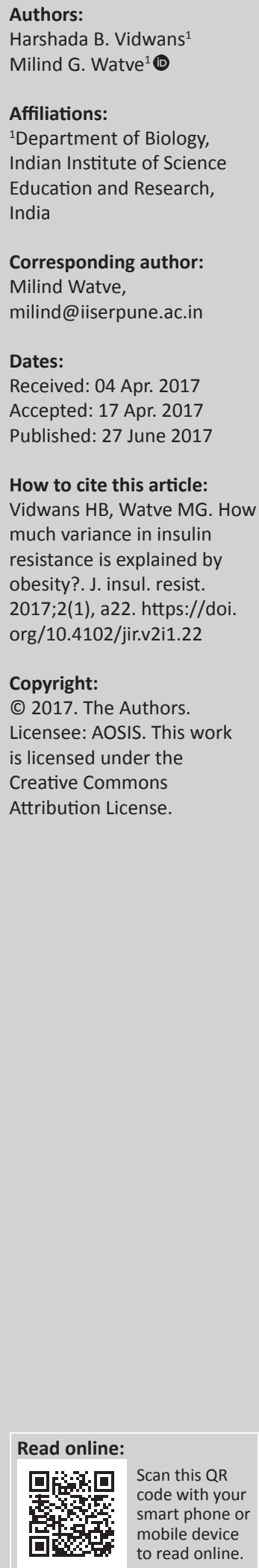

Background: Obesity is believed to be the major cause of insulin resistance, although many other obesity-independent signals are shown to affect insulin sensitivity.

Aim: We address the degree to which variation in insulin resistance is explained by morphometric and biochemical measures of obesity.

Methods: PubMed and Google Scholar were searched for epidemiological studies published between 1994 and 2015 that report correlations between at least one measure of obesity and that of insulin resistance.

Results: A total of 63 studies satisfied inclusion criteria. Frequency distribution of coefficients of determination between morphometric measures of obesity and insulin resistance was skewed with the mode being less than $10 \%$, class and median being $17.3 \%$. Plasma leptin concentration, but not plasma non-esterified fatty acid level, was better correlated with insulin resistance, the median variance explained being 33.29\%. Morphometric measures alone had a median variance explained of $16 \%$. Ethnicity explained part of the variance across studies with the correlation being significantly poorer in Asians.

Conclusion: The extremely limited predictive power of morphometric and biochemical measures of obesity suggests that more research needs to focus on the obesity-independent signals that affect insulin sensitivity as well as leptin expression.

\section{Introduction}

Obesity is currently believed to be the major cause of type 2 diabetes mellitus (T2DM) characterised by insulin resistance. Among the currently perceived risk factors for T2DM, overweight and obesity are strongest. ${ }^{1}$ Adipose tissue, implicated as a major determinant of insulin sensitivity and glucose homeostasis,,$^{2,3}$ is no more considered an energy storage tissue alone and signals from this tissue affect many endocrine and metabolic functions of the body., ${ }^{4,5}$ Various measures of obesity are generally significantly positively correlated with markers of insulin resistance. Although the correlation has different possible causal interpretations, such as hyperinsulinemia being causal to obesity, the mainstream view considers obesity to be the primary cause of insulin resistance. However, the relationship may not be as robust as classically believed.

Obese and metabolically normal individuals exist ${ }^{6,7}$ and their proportion varies substantially between studies ranging from $6 \%$ to $75 \%$ of the obese population. ${ }^{8,9}$ On the other hand, normalweight, insulin-resistant individuals are also frequent. ${ }^{10}$ Across countries, there is no correlation between prevalence of obesity and T2DM. ${ }^{11}$ Indeed, as a prime example, Asians develop T2DM at much lower obesity levels.

Apart from adipocyte-derived signals, a number of other signals have been shown to affect insulin sensitivity partly or completely independent of obesity. They include autonomic and other neuronal signals, ${ }^{12}$ epidermal growth factor, brain-derived neurotrophic factor (BDNF), fibroblast growth factor (FGF) and other growth factor signals. ${ }^{13,14,15,16,17,18}$ Myokines, proteins from muscle tissue, have also been shown to affect insulin sensitivity. ${ }^{19,20,21}$ Damage or soring of muscle reduces insulin sensitivity, an effect that is not restricted to the damaged muscle..$^{22,23,24,25}$ Infections ${ }^{26,27}$ and pain $^{28}$ also affect insulin sensitivity. Thus, it is clear that apart from adiposity-related signals, a number of other mechanisms affect insulin signalling and glucose homeostasis. However, the relative role of obesity-related and obesity-independent signals in influencing the prevalence of insulin resistance in a population remains poorly understood.

We address a part of this broader question by asking how much of the variance in measures of insulin resistance (i.e. fasting plasma insulin, homeostatic model assessment-insulin resistance/ 
insulin sensitivity (HOMA - IR/IS), hyperinsulinaemic clamp and frequently sampled intravenous glucose tolerance test) is explained by obesity indices, namely body mass index (BMI), waist-hip ratio (WHR), waist circumference (WC), total fat (TF), plasma non-esterified fatty acids (NEFA) and plasma leptin, in epidemiological studies published between 1994 and 2015. The systematic review was registered with the International Prospective Register of Systematic Reviews (registration number CRD42016047499). The review design followed Preferred Reporting Items for Systematic Reviews and Meta-analyses guidelines. ${ }^{29}$

\section{Research design and methods Study design}

We conducted a literature search using PubMed (Medline) and Google Scholar for studies examining correlation between obesity and insulin resistance or risk of type 2 diabetes published between 1994 and 2015. The key words used in combination for the search included: Type 2 diabetes mellitus (T2DM), Homeostatic model assessment - insulin resistance/ insulin sensitivity (HOMA - IR/IS), Frequently sampled intravenous glucose tolerance test (FSIVGTT), hyperinsulinaemic clamp, obesity, waist circumference (WC), non-esterified fatty acid (NEFA), leptin, waist-hip ratio (WHR), body mass index (BMI) and total fat (TF). The key word combinations used for search included (1) obesity or one of the specific measures of obesity, (2) insulin resistance or one of the specific measures of insulin resistance and (3) the word 'correlation'. We did not include pro-inflammatory cytokines in the study. Although adipocytes are known to secrete cytokines, they are not specific to adipose tissue. Because many different types of cells secrete proinflammatory cytokines, it would be difficult to draw clearcut inferences from their correlations. Adiponectin is more specific to adipose tissue; however, its plasma level is not directly proportional to obesity. Therefore, we did not consider adiponectin as a surrogate of obesity.

\section{Setting}

The number of patients per study ranged from 21 to 4800 . The studies covered different age groups, the net range being from 2 to 95 years.

\section{Study population and sampling strategy}

Papers reporting Pearson's correlation, Spearman's correlation or multiple regression including one or more measures of obesity and one or more measures of insulin resistance were included in the meta-analysis. Studies that divided the population in groups such as tertiles or quartiles and used group comparison statistics were excluded because different studies make different number of groups making comparisons across studies difficult. Two researchers screened all papers identified in the initial search, based on the inclusion criteria. In addition, the corresponding authors of 35 studies that did not report any correlations between measures of obesity and insulin resistance but had measured these parameters in a population were contacted to request access to raw data from which we could have calculated the required statistics. Four data sets coming from two research groups could be accessed, from which we could obtain 16 relevant correlations.

\section{Data analysis}

Many publications reported more than one correlation based on different measures of obesity and insulin resistance or based on distinct patient groups separated by gender, treatment, ethnicity, etc. As one approach to analysis, every correlation between a measure of obesity and that of insulin resistance was treated as an independent data point. In an alternative approach, to avoid pseudoreplication, we also analysed the data taking only the best correlation from each study. The coefficient of determination $\left(R^{2}\right)$ or variance explained was extracted either as reported by the authors, or we calculated it from the reported data.

\section{Results}

Sixty-three studies were identified using the inclusion and exclusion criteria (see Appendix 1 for the complete list), which gave us 164 correlations between obesity measures and insulin resistance measures. In 10 studies, variance explained was reported, and $R^{2}$ could be calculated from published data from 48 studies and from raw data in 4 data sets.

The $164 R^{2}$ values between measures of obesity parameters and those of insulin resistance ranged widely from 0 to 0.9 (non-significant ones being treated as zero). Frequency distribution (Figure 1) revealed that the mode was in the range of $0 \%-10 \%$, suggesting that in the majority of studies obesity explained only up to $10 \%$ variance in insulin resistance. The median variance explained was $17.3 \%$. Taking 164 correlations from 63 studies involves some amount of pseudo-replication. To test whether the overall low mode

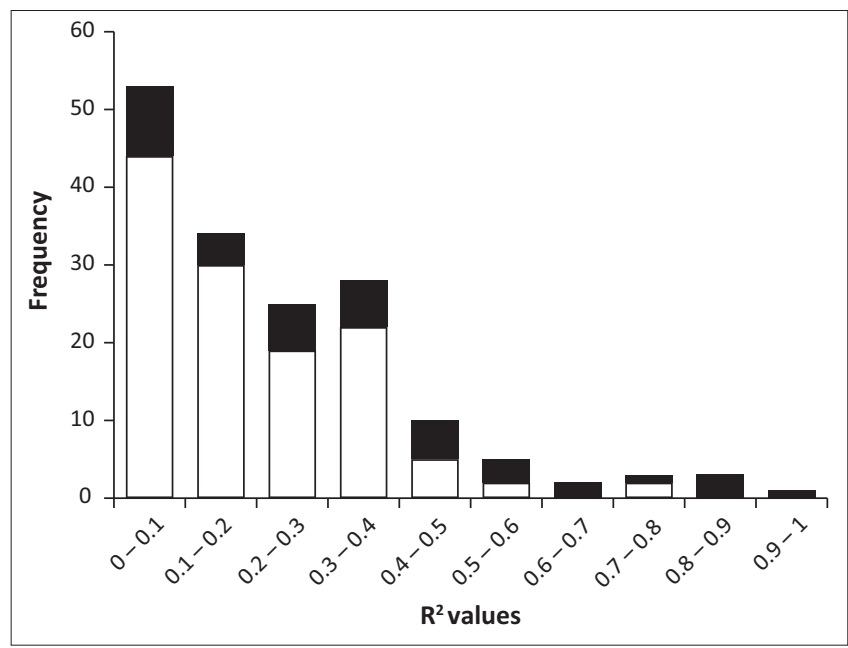

FIGURE 1: Frequency distribution of $R^{2}$ values. For all non-significant correlations, $R^{2}$ was treated as zero. Filled bars indicate correlations with plasma leptin concentrations. Open bars indicate all other correlations. 
and median are artefacts of the pseudo-replication, we selected the largest $R^{2}$ value from each of the 54 studies. The median of this collection was higher $(27.04 \%)$. A rise in the median was expected because the best correlation from every study was taken. It is important to note that despite taking the best, the median variance explained remains small.

Among various obesity-related parameters, leptin had better $R^{2}$ values than the other measures, the difference being significant by the median test (leptin correlations: 30 above the median and 10 below the median, chi-square $=10, p<$ 0.0001). NEFA correlations were significantly worse ( 1 above the median and 13 below, chi square $=10.28, p=0.001)$. WHR (9 below the median 6 above, chi square $=0.6, p=0.438$ ), BMI (22 above the median 23 below, chi square $=0.8, p=0.881$ ), WC (14 below the median 10 above, chi square $=2.02, p=$ 0.414 ) and TF (14 above the median 12 below, chi square = $0.153, p=0.694$ ) did not differ significantly from the global median. Leptin correlated better with insulin resistance parameters and had a median variance explained as $33.29 \%$. For morphometric measures of obesity, the median was 16\%. ${ }^{30}$ Among the morphometric measures, BMI, WHR, WC and TF did not differ significantly from each other in terms of explaining variance in insulin resistance.

Not all studies report $R^{2}$ values in the published paper. We requested authors of 35 such papers to give us access to their raw data so that we could calculate the coefficients. Of the 35 published studies, four data sets from two research groups could be accessed from whose data we could calculate 16 correlations out of which $13 R^{2}$ values were below the median (chi square $=6.25, p=0.01$ ). If the median without leptin was considered, 12 of 16 were below the median (chi square $=4$, $p=0.04$ ). Thus, correlations in unpublished data seemed to be significantly weaker than the published ones.

Of $164 R^{2}$ values, 157 were accompanied by ethnicity information. The median for these 157 was $20.25 \%$. Studies on populations dominated by east Asian ethnicity had $R^{2}$ values significantly below the median (16 below and 4 above the median, chi square $=7.2, p=0.007)$. In studies from populations dominated by South Americans ( 7 above and 3 below the median) (chi square $=1.6, p=0.2$ ), south and central Asians (17 below and 17 above the median) (chi square $=0, p=1$ ), Africans ( 7 below and 2 above the median) (chi square $=2.77, p=0.095)$ and Caucasoid-dominated populations (American, European and Australian white) (32 below and 39 above the median, chi square $=0.69, p=0.406$ ), $R^{2}$ values were not significantly above or below the median.

The age group under study had a significant effect on the strength of the correlations. $R^{2}$ was positively correlated with the midpoint of the age range of the study and more strongly correlated with the width of the age range of the study (Figure 2). This may suggest that obesity is a better predictor of insulin resistance at a later age. Broader age range coverage by itself may strengthen the correlation. There was a positive correlation between age range covered and midpoint of the
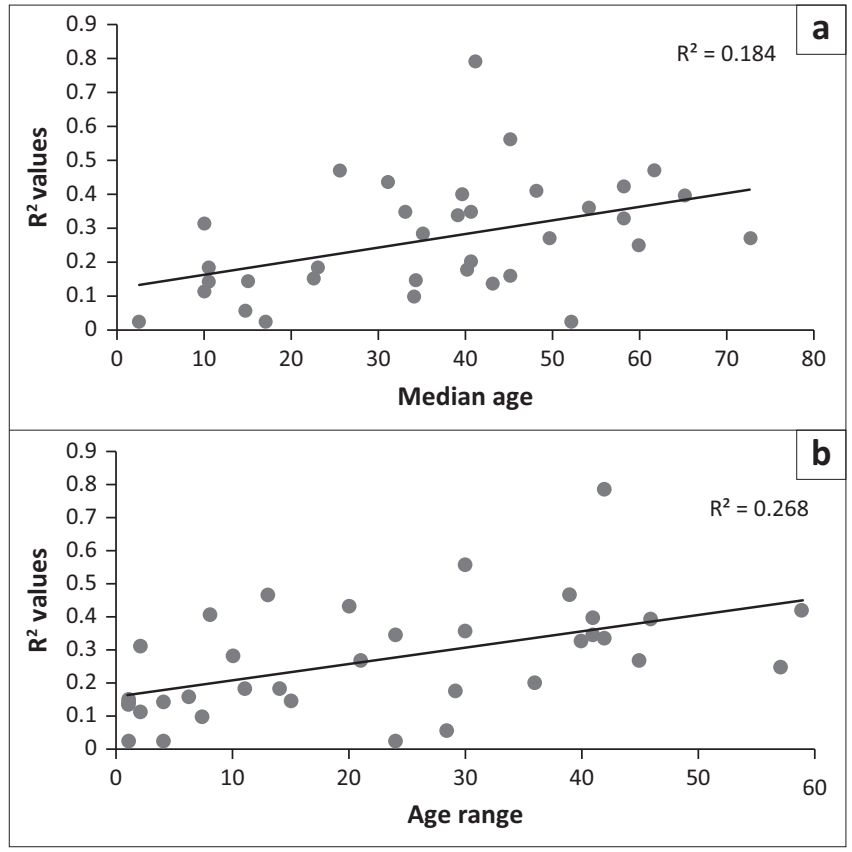

FIGURE 2: Variance in insulin resistance explained by obesity is dependent upon age and age range of the study group. (a) Correlation between mid-point of age range and $R^{2}$ for obesity insulin resistance correlation. (b) Correlation between the width of the age range and $R^{2}$ for obesity insulin resistance correlation.

age range. After correcting for the effect the width of range, the correlation of $R^{2}$ with midpoint age became nonsignificant. Therefore, whether obesity is a better predictor of insulin resistance at a later age is doubtful. The time of publication (calendar year) and sample size did not show significant effects on the variance explained.

\section{Discussion}

The frequency distribution of $R^{2}$ in the studies indicates that the relationship between obesity and insulin resistance is highly variable across studies, but in the majority, the variance explained is quite poor. Populations dominated by east Asians had poorer $R^{2}$ than the global median. A popular interpretation is that in Asians the relationship has a lower intercept and greater slope. ${ }^{11}$ This analysis demonstrates that not only the intercept or the slope of the relation is shifted but also the strength of the correlation is itself much weaker. Furthermore, this difference was noted only in east Asians and was lost when all Asian studies were pooled.

Among the various measures of obesity, all morphometric parameters performed poorly. The notion that central obesity is better correlated with insulin resistance ${ }^{31}$ was not supported as WHR showed even lower predictive power than BMI across studies. Total body fat was also not a consistently better predictor than BMI. Plasma leptin concentration was a much better predictor of insulin resistance, but the relationship between obesity and plasma leptin concentration is not very straightforward. Although leptin is mainly secreted by adipocytes, expression in other tissues including brain, liver, placenta, gastric mucosa, skeletal muscle and mammary epithelium ${ }^{32}$ is known. Leptin expression per unit fat mass is affected by a number of other signals including 
behavioural and sex hormone signalling, fasting, glucocorticoids, thyroid hormone, infections, bacterial endotoxins and cytokines. ${ }^{32}$ At a given adiposity, stress also affects leptin expression. ${ }^{33}$ Many of the factors affecting leptin expression also affect insulin sensitivity. Moreover, leptin expression is known to be stimulated by insulin, ${ }^{34,35,36}$ which makes it likely that at least part of the correlation may reflect reverse causation. Therefore, stronger correlation between leptin and insulin resistance cannot be taken to conclusively support the causal role of obesity in insulin resistance.

It is important to note that among the studies that had not published the $R^{2}$ values, but whose raw data were accessible, the majority of $R^{2}$ values were below the global median. This suggests that there is likely to be a publication bias against reporting low or non-significant correlations. Removing the publication bias may lower the median further.

Overall, in the majority of the studies, both morphometric and biochemical measures of obesity seem to explain only a small part of the variation in insulin resistance. This suggests that there can be other causal factors for insulin resistance independent of obesity. In experimental physiology, a number of signals have been demonstrated that affect insulin sensitivity independent of obesity. ${ }^{13,14,15,16}$ In epidemiological data, factors other than obesity such as socioeconomic status ${ }^{37}$ or individual behaviour ${ }^{38,39}$ are significantly associated with insulin resistance or T2DM. A number of pathways linking behaviour to insulin signalling are reviewed by Watve. ${ }^{40}$ In evolutionary medicine, the classical 'thrift' family of hypotheses have recently received much criticism ${ }^{41}$ and a number of alternative hypotheses for the origins of insulin resistance have been suggested that are not necessarily obesity dependent. They include fertility selection hypothesis of Corbett et al. ${ }^{42}$ and behavioural switch hypothesis of Watve and Yajnik. ${ }^{43}$ A number of hypotheses about intrauterine programming also do not involve obesity as a primary cause of insulin resistance. They include the fast lifecycle hypothesis ${ }^{44}$ or mechanistic target of rapamycin (mTOR) over-activation hypothesis. ${ }^{45}$ The causal relationship between obesity and insulin resistance is also debated. James Neel, the father of thrifty gene hypothesis, did not consider obesity as a cause of type 2 diabetes. ${ }^{46}$ In models of intrauterine growth retardation, hyperinsulinaemia is shown to appear before insulin resistance ${ }^{47}$ and it is possible that hyperinsulinaemia is primary, which leads to insulin resistance on the one hand and obesity on the other. Thus, a number of alternative possibilities exist, but currently, we know little about them because they have not been sufficiently explored.

Our analysis reveals the limited role of obesity and thereby highlights the importance of investigating alternative possibilities. A possible clinical implication of our finding is that obesity control will have only a limited success in preventing type 2 diabetes. More research needs to be focused on the other possible causes of insulin resistance and their importance at the clinical level. Any effort in this direction can be extremely enlightening and useful for the prevention, control and treatment of type 2 diabetes.

\section{Acknowledgements}

The authors would like to thank Manawa Diwekar, Shubhankar Kulkarni and Pramod Patil for useful comments on an earlier draft of the manuscript. They would also like to thank Raj Bhopal and others of the Newcastle Heart project, England, and Chittaranjan Yajnik and others of the Pune Maternal Nutrition study and Coronary Risk of Insulin Sensitivity in Indian Subjects, Pune, study for giving them access to their raw data and also for their useful comments on the manuscript.

\section{Competing interests}

The authors declare that they have no financial or personal relationships which may have inappropriately influenced them in writing this article.

\section{Authors' contributions}

H.B.V. and M.G.W. designed the study. H.B.V. did the search. H.B.V. and M.G.W. did the screening and analysis and wrote the article.

\section{References}

1. World Health Organisation. WHO 2016 Global report on diabetes. April 7, 2016. Available from http://www.who.int

2. Qatanani M, Lazar M. Mechanisms of obesity-associated insulin resistance: Many choices on the menu. Genes Dev. 2007;21:1443-1455. https://doi.org/10.1101/ gad. 1550907

3. Grundy S. Multifactorial causation of obesity: Implications for prevention. Am J Clin Nutr. 1998;67(3):563S-572S

4. Choe S, Huh J, Hwang I, et al. Adipose tissue remodeling: Its role in energy metabolism and metabolic disorders. Front Endocrinol (Lausanne). 2016;13(7):30. https://doi.org/10.3389/fendo.2016.00030

5. Rosan E, Spiegelman B. Adipocytes as regulators of energy balance and glucose homeostasis. Nature. 2006;444(7121):847-853. https://doi.org/10.1038/nature05483

6. Wildman R, Muntner P, Reynolds $K$, et al. The obese without cardiometabolic risk factor clustering and the normal weight with cardiometabolic risk factor clustering prevalence and correlates of 2 phenotypes among the US population (NHANES 1999-2004). Int J Clin Pract. 2008;168(15):592-601. https://doi.org/10.1097/01. ogx.0000338100.83483.58

7. Hayes $L$, Pearce $M$, Firbank $M$, et al. Do obese but metabolically normal women differ in intra-abdominal fat and physical activity levels from those with the expected metabolic abnormalities? A cross-sectional study. BMC Public Health. 2010;10:723. https://doi.org/10.1186/1471-2458-10-723

8. Conus F, Rabasa-Lhoret R, Péronnet F. Characteristics of metabolically obese normal-weight (MONW) subjects. Appl Physiol Nutr Metabol. 2007;32(1):4-12 https://doi.org/10.1139/h06-092

9. Rey-López J, De Rezende L, Pastor-Valero M, Tess B. The prevalence of metabolically healthy obesity: A systematic review and critical evaluation of the definitions used. Obes Rev. 2014;15(10):781-790. https://doi.org/10.1111/obr.12198

10. Ruderman N, Chisholm D, Pi-Sunyer X, Schneider S. The metabolically obese, normal-weight individual revisited. Diabetes. 1998;47(5):699-713. https://doi. org/10.2337/diabetes.47.5.699

11. Yoon K, Lee J, Kim J, et al. Epidemic obesity and type 2 diabetes in Asia. Lancet. 2006;9548(368):1681-1688. https://doi.org/10.1016/S0140-6736(06)69703-1

12. Marino J, Xu Y, Hill J. Central insulin and leptin-mediated autonomic control of glucose homeostasis. TEM. 2011;22(7):275-285. https://doi.org/10.1016/j.tem.2011.03.001

13. Gogg S, Smith U. Epidermal growth factor (EGF) and TGF alpha mimic the effects of insulin in human fat cells and augment down-stream signaling in insulin resistance. J Biol Chem. 2002;277:36045-36051. https://doi.org/10.1074/jbc. M200575200

14. Duan W, Guo Z, Jiang H, Ware M, Mattson M. Reversal of behavioral and metabolic abnormalities and insulin resistance syndrome, by Dietary Restriction in Mice Deficient in Brain-Derived Neurotrophic Factor. Endocrinology. 2003;144(6):24462453. https://doi.org/10.1210/en.2002-0113

15. Miettinen $P$, Ustinov J, Ormio $P$, et al. Down Regulation of EGF receptor signaling in pancreatic islets causes diabetes due to impaired postnatal $\beta$-cell growth Diabetes. 2006;55(12):3299-3308. https://doi.org/10.2337/db06-0413

16. Rogers C, Moukdar F, McGee M, Davis B, et al. EGF receptor (ERBB1) abundance in adipose tissue is reduced in insulin-resistant and type 2 diabetic women. $\mathrm{J}$ Clin Endocrinol Metab. 2012;97(3):E329-E40. https://doi.org/10.1210/jc.2011-1033 
17. Kim H, Lee J, Cha J, et al. Fibroblast growth factor 21 improves insulin resistance and ameliorates renal injuryin db/db mice. Endocrinology.2013:154(9):3366-3376. https://doi.org/10.1210/en.2012-2276

18. Meek T, Wisse B, Thaler J, et al. BDNF action in the brain attenuates diabetic hyperglycemia via insulin-independent inhibition of hepatic glucose production. Diabetes. 2013;62(5):1512-1518. https://doi.org/10.2337/db12-0837

19. Eckardt K, Görgens S, Raschke S, Eckel J. Myokines in insulin resistance and type 2 diabetes. Diabetologia. 2014;57(6):1087-1099. https://doi.org/10.1007/s00125014-3224-x

20. Byunghun $S$, Hee-Jae K, Jinsoo K, Wook $S$. Exercise-induced myokines in health and metabolic diseases. Int Med Res. 2014;3(4):172-179. https://doi. org/10.1016/j.imr.2014.09.007

21. Gamas L, Matafome P. Irisin and myonectin Regulation in the Insulin Resistant Muscle: Implications to adipose tissue: Muscle crosstalk. J Diab Res. 2015; 2015:359159. https://doi.org/10.1155/2015/359159

22. Del Aguila L, Krishnan R, Ulbrecht J, et al. Muscle damage impairs insulin stimulation of IRS-1, PI 3-kinase, and Aktkinase in human skeletal muscle. Am J Physiol Endocrinol Metab. 2000;279:206-212.

23. Costill D. Impaired muscle glycogen resynthesis after eccentric exercise. J Appl Physiol. 1990;69:46-50.

24. Asp S, Richter E. Decreased insulin action on muscle glucose transport after eccentric contractions in rats. J Appl Physiol. 1996;81:1924-1928.

25. Black $P$, Brooks $D$, Bessey $P$, Wolfe R, Wilmore $D$. Mechanisms of insulin resistance following injury. Ann Surg. 1982;196:420-435. https://doi.org/10.1097/00000658 198210000-00005

26. Yki-Jarvinen H, Sammalkorpi K, Koivisto V, Nikkila E. Severity, duration, and mechanisms of insulin resistance during acute infections. J Clin Endocrinol Metab. 1989;69:317-323. https://doi.org/10.1210/jcem-69-2-317.

27. Lang C. Sepsis-induced insulin resistance in rats is mediated by a b-adrenergic mechanism. Am J Physiol Endocrinol Metab. 1992;263:703-711.

28. Greisen J, Juhl C, Grøfte T, Vilstrup H, Jensen T, Schmitz O. Acute pain induces insulin resistance in humans. Anesthesiology. 2001;95:578-584. https://doi. org/10.1097/00000542-200109000-00007

29. Shamseer L, Moher D, Clarke M, et al. Preferred reporting items for systematic review and meta-analysis protocols (PRISMA-P) 2015: Elaboration and explanation. BMJ. 2015;349:g7647. https://doi.org/10.1136/bmj.g7647

30. Johns I, Goff L, Bluck L, et al. Plasma free fatty acids do not provide the link between obesity and insulin resistance or $\beta$-cell dysfunction: Results of the reading, imperial, surrey, Cambridge, Kings (RISCK) study. Diabet Med. 2014; 31(11):1310-1315. https://doi.org/10.1111/dme.12550

31. Golay A, Ybarra J. Link between obesity and type 2 diabetes, Best Pract Res Clin Endocrinol Metab. 2005;19(4):649-663. https://doi.org/10.1016/j.beem.2005.07.010

32. Ahima R, Flier J. Leptin. Annu. Rev. Physiol. 2000;62:413-373. https://doi.org/10. 1146/annurev.physiol.62.1.413
33. Otsuka R, Yatsuya H, Tamakoshi K, Matsushita K, Wada K, Toyoshima H. Perceived psychological stress and serum leptin concentrations in Japanese men. Obesity. 2006;14(10):1832-1838. https://doi.org/10.1038/oby.2006.211

34. Saladin R, Devos P, Guerre-Millo M, Leturge A, Girard J. Transient increase in obese gene expression after food intake or insulin administration. Nature. 1995;377:527529. https://doi.org/10.1038/377527a0

35. Kolaczynski J, Nyce M, Considine R, Boden G, Nolan J, Henry R. Acute and chronic effects of insulin on leptin production in humans: Studies in vivo and in vitro. Diabetes. 1996;45:699-701. https://doi.org/10.2337/diab.45.5.699

36. Boden $G$, Chen X, Kolacynski J. Effects of prolonged hyperinsulinemia on serum leptin in normal human subjects. J Clin Invest. 1997;100:1107-1113. https://doi. org/10.1172/JCl11962

37. Buitrago-Lopez A, Van den Hooven E, Rueda-Clausen C, et al. Socioeconomic status is positively associated with measures of adiposity and insulin resistance, but inversely associated with dyslipidaemia in Colombian children. J Epidemiol Community Health. 2015;9(6):580-587. https://doi.org/10.1136/jech-2014-204992

38. Thompson E, Muller M, Wrangham R, Lwanga J, Potts K. Urinary C-peptide tracks seasonal and individual variation in energy balance in wild chimpanzees. Horm Behav. 2009;55:299-305. https://doi.org/10.1016/j.yhbeh.2008.11.005

39. Joshi A, Kondekar S, Belsare $P$, et al. People with metabolic syndrome disorders give lower offers in ultimatum game. Psychology. 2010;1:128-133. https://doi. org/10.4236/psych.2010.12017

40. Watve MG. Doves, diplomats and diabetes: A Darwinian interpretation of type 2 diabetes and related disorders. New York: Springer; 2013.

41. Watve M, Diwekar-Joshi M, What to expect from an evolutionary hypothesis for a human disease: The case of type 2 diabetes. Homo - J Comp Hum Biol. 2016;67(5):349-368

42. Corbett S, McMichael A, Prentice A. Type 2 diabetes, cardiovascular disease, and the evolutionary paradox of the polycystic ovary syndrome: A fertility first hypothesis. Am J Hum Biol. 2009:21:587-598. https://doi.org/10.1002/ ajhb.20937

43. Watve $M$, Yajnik C. Evolutionary origins of insulin resistance: A behavioral switch hypothesis. BMC Evol Biol. 2007;7:61. https://doi.org/10.1186/1471-2148-7-61

44. Stipp D. Linking nutrition, maturation and aging: From thrifty genes to the spendthrift phenotype. Aging (Milano). 2011;3:85. https://doi.org/10.18632/ aging.100286

45. Blagosklonny M. TOR-centric view on insulin resistance and diabetic complications: Perspective for endocrinologists and gerontologists. Cell Death Dis. 2013;4:e964 https://doi.org/10.1038/cddis.2013.506

46. Neel JV. Diabetes mellitus: A 'thrifty' genotype rendered detrimental by 'progress'? Am J Hum Genet. 1962;14:353-362.

47. Chakravarthy M, Zhu Y, Wice M, et al. Decreased fetal size is associated with betacell hyperfunction in early life and failure with age. Diabetes. 2008;57:2698-2707. https://doi.org/10.2337/db08-0404 


\section{Appendix 1: Sixty-three studies used to identify the inclusion and exclusion criteria}

1. Abate N, Chandalia M, Snell P, Grundy S. Adipose Tissue Metabolites and Insulin Resistance in Nondiabetic Asian Indian Men. J Clin Endocrinol Metab. 2004 Jun;89(6):2750-5.

2. Ades A, Savage P, Toth M, Schneider D, Audelin M, Bunn J, Ludlow M. The influence of obesity and consequent insulin resistance on coronary risk factors in medically treated patients with coronary disease. International Journal of Obesity. 2008; 32:967-974.

3. Baldeweg S, Golay A, Natali A, Balkau B, Del Prato S, Coppack SW. Insulin resistance, lipid and fatty acid concentrations in 867 healthy Europeans. European Group for the Study of Insulin Resistance (EGIR). Eur J Clin Invest. 2000 Jan;30(1):45-52.

4. Bhopal R, Unwin N, White M, Yallop J, Walker L, Alberti K, Harland J, Patel S, Ahmad N, Turner C. Heterogeneity of coronary heart disease risk factors in Indian, Pakistani, Bangladeshi, and European origin populations: Cross sectional study. BMJ. 1999;319:215-220.

5. Broussard J, Chapotot F, Abraham V, Day A, Delebecque F, Whitmore H, Tasali E. Sleep restriction increases free fatty acids in healthy men. Diabetologia. 2015; 58:791-798. DOI:10.1007/s00125-015-3500-4

6. Calcutt N, Jolivalt C, Fernyhough P. Growth factors as therapeutics for diabetic neuropathy. Curr Drug Targets. 2008;9(1):47-59.

7. Carey D, Jenkins A, Campbell L, Freund J, Chisholm D. Abdominal Fat and Insulin Resistance in Normal and Overweight Women Direct Measurements Reveal Strong Relationship in Subjects at Both Low and High Risk of NIDDM. DIABETES. 1996;45:633-638.

8. Cho Y, Kang J, Hur Y, Song J, Lee K. Related Factors of Insulin Resistance in Korean Children: Adiposity and Maternal Insulin Resistance Int. J. Environ. Res. Public Health. 2011;8:4596-4607.

9. Contreras P, Zura M, Aguirre C, Sepúlveda A, Depix M, Mella I. The clinical estimate of adiposity is not a good predictor of insulin tissue sensitivity measured with a minimal model analysis. Rev Med Chil. 1994 Mar;122(3):241-7.

10. Coutinho P, Leite N, Lopes W, Rosa da Silva L, Consentino C, Araújo C, Moraes Jr F, de Jesus I, Cavaglieri C, Radominski R. Association between adiposity indicators, metabolic parameters and inflammatory markers in a sample of female adolescents. Arch Endocrinol Metab. 2015;59(4):325-334.

11. Dagogo-Jack S, Fanelli C, Paramore D, Brothers J, Landt M. Plasma Leptin and Insulin Relationships in Obese and Nonobese Humans. Diabetes. 1996;45(5): 695-698.

12. Daruka K. Correlation of body fat index with insulin resistance across normal overweight and obese individuals. Journal of Evidence based Medicine and Healthcare. 2015;23(2):3422-3426.

13. Fischer S, Hanefeld M, Haffner S, Fusch C, Schwanebeck U, Köhler C, Fücker K, Julius U. Insulin-resistant patients with type 2 diabetes mellitus have higher serum leptin levels independently of body fat mass. Acta Diabetol 2002;39(3):105-10.

14. Fris S, Rössner S, Norgren S, Arvidson J, Gustafsson J. Bone Marrow Transplantation, Glucose metabolism and body composition in young adults treated with TBI during childhood. 2011;46:1303-1308.

15. Gannar F, Cabrera L, Marzougui F, Sakly M, Attia N. Leptin, Insulin and Lipid Profiles in Obese Subjects with and without Metabolic Syndrome in the Region of Profiles in Obese Subjects with and without Metabo

16. García-Estévez D, Araú jo-Vilar D, Saavedra-González A, Fiestras-Janeiro G, Cabezas-Cerrato J. Analysis of the Relationship Between Body Mass Index, Insulin Resistance, and Beta-Cell Function: A Cross-Sectional Study Using the Minimal Model. Metabolism. 2004;53(11):1462-1466.

17. Goto M, Morita A, Goto A, Deura K, Sasaki S, Aiba N. Reduction in Adiposity, B-Cell Function, Insulin Sensitivity, and Cardiovascular Risk Factors: A Prospective Study among Japanese with Obesity. PLoS ONE. 2013;8(3):e57964.

18. Hattori A, Iwata A, Uemura K, Miura H, Ueda M, Tamaya T, Muraguchi M, Ohmoto $Y$, Iguchi A. Gender-Related Difference in Relationship between Insulin Resistance and Serum Leptin Level in Japanese Type 2 Diabetic and Non-Diabetic Subjects. Endocrine Journal. 2000;47(5):615-621.

19. Haupt D, Fahnestock P, Flavin K, Schweiger J, Stevens A, Hessler M, Maeda J, Yingling $M$, Newcomer $J$. Adiposity and insulin sensitivity derived from intravenous glucose tolerance tests in antipsychotic-treated patients. Neuropsychopharmacology. 2007;32(12):2561-9.

20. Hayashi T, Boyko E, McNeely M, Leonetti D, Kahn S, Fujimoto W. Visceral Adiposity, Not Abdominal Subcutaneous Fat Area, Is Associated With an Increase in Future Insulin Resistance in Japanese Americans. Diabetes. 2008;57:1269-1275.

21. Henderson D,Fan X, Sharma S, Copeland P, Borba C, Freudenreich O, Cather C, Evin $E$, Donald D. Waist Circumference Is the Best Anthropometric Predictor for Insulin Resistance in Nondiabetic Patients with Schizophrenia Treated with Clozapine But Not Olanzapine J Psychiatr Pract. 2009 Jul;15(4):251-261

22. Hettehewa L, Dharmasiri L, Ariyaratne $C$, Jayasinghe $S$, Weeraratne $T$, Kotapola I. Correlation between BMI and Insulin resistance in type 2 diabetes mellitus patients pioglitozone in treatment. Galle Medical Journal. 2007;12(1):18-24.

23. Innocent O, ThankGod O, Sandra E, Josiah I. Correlation between body mass index and blood glucose levels among some Nigerian undergraduates. HOAJ Biology. 2013;2(4):1-4.
24. Karpe F, Dickmann J, Frayn K. Fatty Acids, Obesity, and Insulin Resistance: Time for a Reevaluation. DIABETES. 2011;60:2441-2449.

25. Khokhar K, Sidhu S, Kaur G. Relationship between serum leptin and type 2 diabetes mellitus and their association with obesity and menopausal status. Archives of Applied Science Research. 2013;5(5):38-44.

26. Kiani A. Temporal Changes in Plasma Concentration of Leptin, IGF-1, Insulin and Metabolites Under Extended Fasting and Re-Feeding Conditions in Growing Lambs. Int J Endocrinol Metab. 2013:11.

27. Koebnick C, Roberts C, Shaibi G, Kelly L, Lane L, Toledo-Corral C, Davis C, Ventura E, Alexander K, Weigensberg M, Goran M. Adiponectin and Leptin are Independently Associated with Insulin Sensitivity, but not with Insulin Secretion or Beta-cell Function in Overweight Hispanic Adolescents. Horm Metab Res. 2008.

28. Krekoukia M, Nassis G, Psarra G, Skenderi K, Chrousos G, Sidossis L. Elevated tota and central adiposity and low physical activity are associated with insulin resistance in children. Metabolism. 2007;56(2):206-13.

29. Lalia A, Dasari S, Johnson M, Robinson M, Konopka A, Distelmaier K, Port J, Glavin M, Esponda R, Nair K, Lanza I. Predictors of whole-body insulin sensitivity across ages and adiposity in adult humans. J Clin Endocrinol Metab. 2016 101(2):626-634.

30. Lichnovska C, Gwozdziewiczova S, Chlup R, Hřebiček J, Lichnovska R, Gwozdziewiczova S, Chlup R, Hřebiček J. Serum leptin in the development of insulin resistance and other disorders in the metabolic syndrome. Biomed. Papers 2005;149(1):119-126.

31. Lofgren I, Herron K, Zern T, West T, Patalay M, Shachter N, Koo S, Fernandez M. Waist Circumference Is a Better Predictor than Body Mass Index of Coronary Heart Disease Risk in Overweight Premenopausal Women. J. Nutr. 2004;134(5): 1071-1076.

32. Maffeis C, Corciulo $N$, Livieri C, Rabbone I, Trifirò G, Falorni A, Guerraggio L, Peverelli $P$, Cuccarolo $G$, Bergamaschi $G$, Di Pietro M Grezzani A. Waist circumference as a predictor of cardiovascular and metabolic risk factors in obese girls European Journal of Clinical Nutrition. 2003;57:566-572.

33. Mari A, Ludvik B, Pacini G, Nolan J, Murphy E. A model-based method for assessing insulin sensitivity from the oral glucose tolerance test. Diabetes Care. 2001;24: 539-548.

34. Maria Do Carmo M, Martins, Faleiro L, Fonseca F. Relationship between leptin and body mass and metabolic syndrome in an adult population Rev Port Cardiol. 2012; 31:711-9.

35. Maryam K, Nahid Arian pour N, Aghdas Safari A, Roozegar R. Body mass index (BMI) related insulin resistance in polycystic ovarian syndrome among patients referred to gynecology clinic of Imam Reza Hospital, Tehran, Iran. Journal of Clinical Medicine and Research. 2012;4(7):84-88.

36. Matos L, De Vieira Giorelli G, Dias C. Correlation of anthropometric indicators for identifying insulin sensitivity and resistance. Med J. 2011;129(1):30-5.

37. McLachlan K, Boston R, Alford P. Impaired non-esterified fatty acid suppression to intravenous glucose during late pregnancy persists postpartum in gestational diabetes: A dominant role for decreased insulin secretion rather than insulin resistance Diabetologia. 2005;48:1373-1379.

38. Mohammadzadeh G, Zarghami N. Serum leptin level is reduced in non-obese subjects with type 2 diabetes. Endocrinol Met b. 2013;11(1):3-10.

39. Mohiti J, Afkhami M, Babaei A. Relation Between Leptin and Insulin In Patients With Type II Diabetes Mellitus. Int J Endocrinol Metab. 2005;3:121-125.

40. Nomair A, Aref N, Rizwan F, Ezzo O, Hassan A. Serum leptin level in obese women with polycystic ovary syndrome, and its relation to insulin resistance. Asian Pacific Journal of Reproduction. 2014;3(4):288-294.

41. Okumura T, Taniguchi A, Nagasaka S, Sakai M, Fukushima M, Kuroe A, Yoshii S, Nakamura T, Ogura M, Atarashi T, Nishida S, Nakai Y. Relationship of regional adiposity to serum leptin level in nonobese Japanese type 2 diabetes patients. Diabetes Metab. 2003:29(1):15-8.

42. Pehlivanov B, Mitkov M. Serum leptin levels correlate with clinical and biochemical indices of insulin resistance in women with polycystic ovary syndrome. The European Journal of Contraception \& Reproductive Health Care. 2009;14(2): 153-159.

43. Pitteloud N, Mootha V, Dwyer A, Hardin M, Lee H, Eriksson K, Tripathy K, Yialamas M, Groop L, Elahi D, Hayes F. Relationship between testosterone levels, insulin sensitivity, and mitochondrial function in men. Diabetes Care. 2005;28:1636-1642.

44. Racette S, Evans E, Weiss E, Hagberg J, Holloszy J. Abdominal Adiposity Is a Stronger Predictor of Insulin Resistance Than Fitness Among 50-95 Year Olds. Diabetes Care. 2006;29(3):673-678.

45. Ramakrishnan G, Unni U, Raj T, Thomas T, Vaz M, Kurpad A. A pilot study on hyperinsulinaemic euglycaemic clamp based insulin sensitivity in young adult Indian males with low body mass index. Indian J Med Res. 2009;129:409-417.

46. Rasmussen-Torvik L, Pankow J, David R. Jacobs, Jr, Julia Steinberger, Antoinette Moran, Alan R. Sinaiko Influence of waist on adiponectin and insulin sensitivity in adolescence. Obesity (Silver Spring). 2009;17(1):156-161

47. Reyes M, Gahagan S, Díaz E, Blanco E, Leiva L, Lera L, Raquel Burrows $R$. Relationship of Adiposity and Insulin Resistance Mediated by Inflammation in a Group of Overweight and Obese Chilean Adolescents. Nutrition Journal. 2011;10(1):4.

48. Shea S, Aymong E, Zybert P, Shamoon H, Tracy R, Deckelbaum R, Basch C. Obesity, Fasting Plasma Insulin, and $C$ - reactive protein Levels in Healthy Children. Obesity Research. 2003;11(1):95-103.

49. Sierra-Johnson J, Johnson B, Bailey K, Turner S. Relationships between Insulin Sensitivity and Measures of Body Fat in Asymptomatic Men and Women. Obesity Research. 2004;12(12):2070-2079. 
50. Sivitz W, Wayson S, Bayless M, Larson L, Sinkey C, Bar R, Haynes W. Leptin and Body Fat in Type 2 Diabetes and Monodrug Therapy. The Journal of Clinical Endocrinology \& Metabolism. 2003;88(4):1543-1553.

51. Tabata S, Yoshimitsu S, Hamachi T, Abe I, Ohnaka K, Kono S. Waist circumference and insulin resistance: A cross-sectional study of Japanese men. BMC Endocrine Disorders. 2009;9:1.

52. Temel I, Celik O, Hascalik S, Celik N, Sahin I, Aydin S. Serum nonesterified fatty acids, ghrelin, and homocysteine levels in women with polycystic ovary syndrome. Turk J Med Sci. 2010;40(2):221-228.

53. Thompson D, Boyne M, Ferguson $T$, Reid M, Wilks R, Barnett A, Forrester T. Limitations of fasting indices in the measurement of insulin sensitivity in AfroCaribbean adults. BMC. Research Notes 2014:7:98.

54. Toft I, Bønaa K, Jenssen T. Insulin Resistance in Hypertension Is Associated With Body Fat Rather Than Blood Pressure. Hypertension. 1998;32:115-122.

55. Trirogoff M, Shintani A, Himmelfarb J, Ikizler T. Body mass index and fat mass are the primary correlates of insulin resistance in nondiabetic stage 3-4 chronic kidney disease patients. Am J Clin Nutr. 2007;86:1642-8.

56. Valtueña $S$, Numeroso $F$, Ardigò $D$, Pedrazzoni M, Franzini L, Piatti P, Monti L, Zavaroni I. Relationship between leptin, insulin, body composition and live steatosis in non-diabetic moderate drinkers with normal transaminase levels. European Journal of Endocrinology. 2005;153:283-290.
57. Venkataraman K, Khoo C, Leow M, Khoo E, Isaac A. New Measure of Insulin Sensitivity Predicts Cardiovascular Disease Better than HOMA Estimated Insulin Resistance. PLOS ONE. 2013;8(9):e74410.

58. Virtanen $K$, lozzo $P$, Hällsten $K$, Huupponen R, Parkkola R, Janatuinen T, Lönnqvist F, Viljanen T, Rönnemaa T, Lönnroth P, Knuuti J, Ferrannini E, Nuutila. Increased fat mass compensates for insulin resistance in abdominal obesity and type 2 diabetes: A positron-emitting tomography study. Diabetes. 2005;54(9):2720-6

59. Yadav A, Jyoti P, Jain S, Bhattacharjee S. Correlation of Adiponectin and Leptin with Insulin Resistance: A Pilot Study in Healthy North Indian Population. Indian J Clin Biochem. 2011 Apr;26(2):193-196.

60. Yajnik C, Joglekar C, Lubree H, Rege S, Naik, S, Bhat D, Uradey B, Raut K, Shetty P, Yudkin J. Adiposity, inflammation and hyperglycaemia in rural and urban Indian men: Coronary Risk of Insulin Sensitivity in Indian Subjects (CRISIS) Study. Diabetologia. 2008;51:39-46.

61. Yajnik C. Early Life Origins of Insulin Resistance and Type 2 Diabetes in India and Other Asian Countries. J. Nutr. 2008;134:205-210.

62. Zimmet $P$, Hodge A, Nicolson M, Staten M, De Courten M, Moore J, Morawiecki A, Lubina J, Collier G, Alberti G, Dowse G. Serum leptin concentration, obesity, and insulin resistance in Western Samoans: cross sectional study. BMJ. 1996;313(7063):965-9.

63. Johns I, Goff L, Bluck L, Griffin B, Jebb S, Lovegrove J, Sanders T, Frost G, Dornhorst A. Plasma free fatty acids do not provide the link between obesity and insulin resistance or $\beta$-cell dysfunction: results of the Reading, Imperial, Surrey, Cambridge, Kings (RISCK) study. Diabet Med. 2014;31(11):1310-5. 